\title{
AOR
}

Selected Papers of \#AolR2021:

The 22nd Annual Conference of the

Association of Internet Researchers

Virtual Event / 13-16 Oct 2021

\section{INDEPENDENT AUTHORS' DEPENDENCE ON BIG TECH: CATEGORIZATION AND GOVERNANCE OF AUTHORS OF COLOR ON AMAZON}

Claire Parnell

University of Melbourne

\section{Introduction}

Authors who publish their books outside traditional houses are referred to as independent (or 'indie') authors or self-publishers. These authors are not reliant on traditional gatekeepers-publishers, editors, and costly printing and distribution-to publish and disseminate their creative works. While self-publishing predates the internet, digital book publishing platforms like Amazon Kindle Direct Publishing (KDP), Kobo Writing Life, and Apple iBooks are often lauded for enabling independent producers unconnected to established publishers to enter the book industry. Despite the appellation, independent authors are not completely autonomous. Book publishing on digital platforms is intensely mediated by the technology companies on which authors rely to publish and disseminate their work. Platforms like Amazon mediate authorial and reader-consumer experiences through their technology architecture, algorithms, governance and categorization systems, and economic models (van Dijck, 2013).

Amazon's KDP is the largest platform for self-publishing. Since launching both its selfpublishing platform and Kindle ereader in 2007, Amazon has dominated both the selfpublishing and ebook market (McGurl, 2016). Industry research shows that this sector of the publishing industry is growing; 1.68 million print and ebooks were self-published in 2018, showing a $40 \%$ increase from the previous year (Bowker, 2019). The growth of self-publishing and the ebook market is particularly important for people of color who have historically been marginalised in the publishing industry. According to the 2019 Lee \& Low Diversity Baseline survey, $5 \%$ of US publishing industry professionals are Black/Afro-American/Afro Caribbean. Accessibility for authors of color is also very low. In the romance genre, the largest and most profitable genre globally, just $8.3 \%$ of books published by the leading American romance publishers in 2019 were written by people of color.

Suggested Citation (APA): Parnell, C. (2021, October). Independent Authors' Dependence on Big Tech: Categorization and Governance of Authors of Color on Amazon. Paper presented at AolR 2021: The 22nd Annual Conference of the Association of Internet Researchers. Virtual Event: AolR. Retrieved from http://spir.aoir.org. 


\section{Framework and Methods}

This paper explores Amazon's categorization and content moderation processes as they relate to the work of Black self-published romance authors and argue that Amazon perpetuates the discrimination Black authors face within the publishing industry. This research asks: how does Amazon mediate the work of independent authors through its categorization and governance systems, and what impact does this have on book culture and Amazon's ecommerce role more broadly?

The critical framework for this research combines media and platform studies with publishing studies. Publishing studies is a scholarly discipline that examines the production, circulation and reception of books and shares concerns and methods with the adjacent fields of media studies, reception studies and book history. This research applies an ecology model to map the microsystem of individual book publishing platforms as well as the broader media landscape in which they operate (van Dijck, 2013). This conceptual model enables and understanding of the distinctive features of book publishing platforms and their influence on the processes of production and reception online. It also allows an investigation into the technological, economic and socio-cultural contexts in which books and authors circulate online. This paper uses a mixed-methods approach consisting of interviews with authors of color and website analysis that collected metadata from Amazon's Web API.

\section{Findings and Significance}

The placement of books in Amazon's online marketplace is based on a variety of metadata input by authors, including browse categories, book descriptions, keywords and author information. Amazon's browse categories replicate traditional classification systems, including BISAC (Book Industry Standards and Communications) codes, by designating literature by and about culturally marginalised groups as other from a 'General', unspecified but supposedly white, classification. This research shows that, in addition to metadata provided by independent authors, Amazon uses profile data of authors, including author photos, biographies and metadata linked to other books from the same account, to determine how books should be categorized in its ecommerce system. In one instance, Amazon's systems continued to override the classifications made by an author interviewed for this research until they changed their profile image from an author headshot to their logo. This form of technological redlining replicates systems of marginalisation in the book industry (Noble, 2018).

Amazon also mediates the publishing practices by independent Black authors through their content moderation system. Books published via KDP are subject to both human and computational systems of review and organisation. Amazon applies a proactive review system to these books that looks at the cover, the description, author, title, the categories, and the tags, but does not read or scan the text for offensive material. It also applies a retroactive editorial review system for comments and books that users have flagged for violating terms of service (Gillespie, 2018). A cover for a title by one author interviewed for this research was flagged as 'adult material' by Amazon's machine learning moderation system, Rekognition, and the book was prevented from being 
published through KDP. The cover may be considered suggestive but not lewd within the context of romance fiction genre conventions.

The author appealed this decision with Amazon's author services and eventually the book was made available on Amazon.com. However, although it is technically available for sale across Amazon's global marketplace, it has been suppressed from the site's search engine results. Content deemed 'adult material' is excluded from Amazon's search tool and their sales ranking (Gillespie, 2018). This demonstrates the technological capabilities Amazon must suppress books and highlights a distinction between the explicit rejection of content and implicit suppression of content within its ecosystem.

This finding has broader implications for the use of Amazon's moderation technology. Rekognition, like many automatic detection software that have been programmed to identify human images, has been proven to be substantially less accurate in accurately identifying darker-skinned individuals, particularly darker-skinned women (Buolamwini \& Gebru, 2018). This algorithmic bias has consequences far beyond books published and sold on Amazon. Although Amazon announced a one-year moratorium on police use of Rekognition, it has historically been widely used by US police agencies and the military. Amazon acts as a powerful intermediary in the governance and organisation of content in its marketplace. The implicit suppression of authors' books and categorization redlining is wholly based on the increased datafication of books by Amazon. This has major implications for the discoverability of these books and, consequently, author sales. Amazon replicates systems of oppression against authors of color who have been historically marginalised in the book publishing industry.

\section{References}

Buolamwini, J \& Gebru, T 2018, 'Gender Shades: Intersectional Accuracy Disparities in Commercial Gender Classification', Proceedings of Machine Learning Research, vol. 81, no. 1, pp. 1-15.

Bowker 2019, Self-Publishing in the United States, 2013-2018: Print and Ebooks, Bowker \& ProQuest, USA.

Gillespie, T 2018, Custodians of the Internet: Platforms, Content Moderation, and the Hidden Decisions that Shape Social Media, Yale University Press, USA.

Lee \& Low 2019, Diversity in Publishing 2019: Diversity Baseline Survey 2.0, Lee \& Low Books, USA.

McGurl, M 2016, 'Everything and Less: Fiction in the Age of Amazon', Modern Language Quarterly, vol. 77, no. 3, pp. 447-471.

Noble, SU 2018, Algorithms of Oppression, New York University Press, NY, USA.

The Ripped Bodice 2019, The State of Racial Diversity in Romance Publishing 2019, The Ripped Bodice, USA. 
van Dijck, J 2013 The Culture of Connectivity: A Critical History of Social Media, Oxford University Press, USA. 